\title{
Complex orthodontic and surgical management of an adult patient with transverse maxillary deficiency and skeletal class III malocclusion: A case report
}

\section{Kompleksowe leczenie ortodontyczno-chirurgiczne pacjentki dorosłej z niedorozwojem poprzecznym szczęki i IIII klasą szkieletową - opis przypadku}

\author{
Rafał Nowak ${ }^{1, A-F}$, Małgorzata Rzepecka-Skupień2,B-D, Ewa Zawiślak ${ }^{2, C-E}$ \\ ${ }^{1}$ Department of Maxillofacial Surgery, Wroclaw Medical University, Poland \\ ${ }^{2}$ Department of Maxillofacial Orthopedics and Orthodontics, Wroclaw Medical University, Poland \\ A - research concept and design; $B$ - collection and/or assembly of data; $C$ - data analysis and interpretation; \\ $D$ - writing the article; $E$ - critical revision of the article; $F$ - final approval of the article
}

Address for correspondence

Rafał Nowak

E-mail: rafal.nowak@chirurgiatwarzy.pl

Funding sources

None declared

Conflict of interest

None declared

Received on July 25, 2019

Reviewed on September 11, 2019

Accepted on September 25, 2019

Published online on March 4, 2020

Cite as

Nowak R, Rzepecka-Skupień M, Zawiślak E.

Complex orthodontic and surgical management of an adult

patient with transverse maxillary deficiency and skeletal

class III malocclusion: A case report. Dent Med Probl.

2020;57(1):103-109. doi:10.17219/dmp/112574

DOI

$10.17219 / \mathrm{dmp} / 112574$

Copyright

๑ 2020 by Wroclaw Medical University

This is an article distributed under the terms of the

Creative Commons Attribution 3.0 Unported License (CC BY 3.0)

(https://creativecommons.org/licenses/by/3.0/)

\begin{abstract}
Skeletal deformities constitute a relatively common structural and functional craniofacial abnormality. The chief complaints reported by patients include a lack of satisfaction with facial appearance, difficulty with breathing or eating, and altered speech. The management of skeletal malocclusion requires a complex orthodontic and surgical approach.

The paper presents the case of a 28-year-old woman with maxillary constriction and skeletal class III malocclusion. Transpalatal distraction (TPD), based on the distraction osteogenesis phenomenon, was used for correcting transverse maxillary deficiency by increasing the maxillary bone base, and therefore the transverse maxillary dimension. The next stage was orthodontic treatment, involving dentoalveolar decompensation, as part of preparation for bimaxillary osteotomy (BIMAX). The last stage of the complex treatment was BIMAX, which ultimately eliminated skeletal defects in both the sagittal and frontal planes. This complex multidisciplinary management significantly improved facial harmony, increased nasal volume, caused a shiff from mouth breathing to nasal breathing, and restored normal occlusal relationships.
\end{abstract}

Key words: orthognathic surgery, orthodontics, skeletal maxillary constriction, skeletal deformities Słowa kluczowe: chirurgia ortognatyczna, ortodoncja, zwężenie szczęki, wady gnatyczne 


\section{Introduction}

Skeletal malocclusion is commonly encountered in orthodontics. These are craniofacial structural abnormalities involving 1 or more planes. As in the case of all structural abnormalities, skeletal defects always cause some degree of dysfunction. The chief complaints reported by patients include a lack of satisfaction with facial appearance, difficulty in breathing or eating, and altered speech. ${ }^{1-3}$ A multidisciplinary approach is becoming the treatment of choice due to the orthodontists' growing knowledge of available treatment options for skeletal malocclusion on one hand, and the patients' expectations of improved facial esthetics and function on the other hand.

Orthognathic surgery is a subdomain of craniomaxillofacial surgery, which deals specifically with correcting skeletal malocclusion. Surgical treatment involves typical craniofacial osteotomy procedures and determining proper spatial relationships, followed by the fixation of the osteotomized fragments in the predetermined position by means of osteosynthesis. ${ }^{4-6}$

Another important element in the management of skeletal malocclusion is distraction osteogenesis, used for increasing the bone base in order to lengthen a particular facial bone element. It is achieved by using different extraand intraoral distractors. ${ }^{7}$

\section{Case report}

A 28-year-old healthy female was referred to the Department of Maxillofacial Surgery of Wroclaw Medical University in Poland due to significant malocclusion. The patient brought her current plaster models, orthopantomogram (OPG), lateral cephalometric radiograph (Fig. 1), posteroanterior (PA) cephalogram, and computed tomography $(\mathrm{CT})$ scans for the appointment.

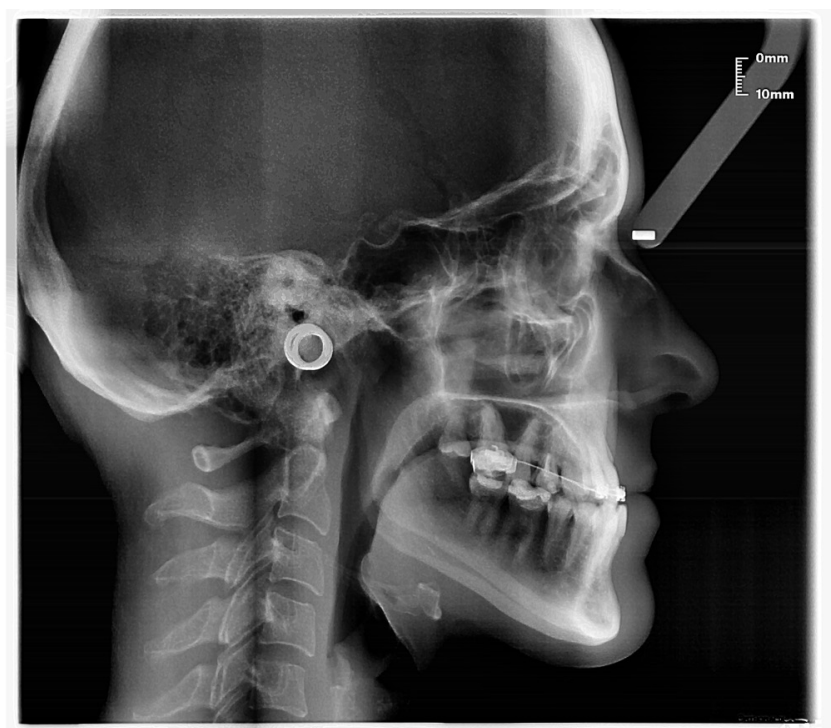

Fig. 1. Lateral cephalogram before treatment
After the clinical assessment and evaluation of the available plaster models, extra- (Fig. 2) and intraoral photographs (Fig. 3), radiographs, and CT scans with three-dimensional (3D) image rendering as well as the cephalometric SegnerHasund analysis, the patient was diagnosed with:

- class III skeletal malocclusion - maxillary retrognathia and mandibular prognathia;

- vertical and transverse maxillary deficiency - vertical maxillary hypoplasia;

- right mandibular laterognathism;

- dental malocclusion.

The patient was offered a multidisciplinary management plan, involving orthodontic treatment and 2 surgical procedures.

The $1^{\text {st }}$ procedure, after the preliminary orthodontic treatment, was transpalatal distraction (TPD), aiming at increasing the transverse maxillary dimension. The next step, after the decompensation of dentoalveolar malocclusion, was bimaxillary osteotomy (BIMAX), performed in order to achieve the optimal spatial and occlusal relationships of the craniofacial structures, and thus to improve the facial profile. Additionally, the patient was advised on the intervals between the 2 procedures, and educated about the potential complications and difficulties as well as the anticipated treatment outcomes.

After the patient gave her informed written consent, the $1^{\text {st }}$ stage of treatment was commenced.

Due to the skeletal nature of transverse maxillary deficiency and the patient's age, we decided to abandon orthodontic treatment aiming at increasing the transverse maxillary dimension.

Maxillary constriction is clinically manifested as a complete unilateral or bilateral crossbite, a narrow palate and a V-shaped high palatal vault, dark buccal corridors, the compensatory buccal inclination of the lateral teeth, and mouth breathing. ${ }^{8,9}$ The presence of at least 2 of the above features indicates the skeletal nature of malocclusion, which determines the subsequent management. Transverse maxillary deficiency jeopardizes the stability of surgical treatment outcomes in patients with skeletal malocclusion.
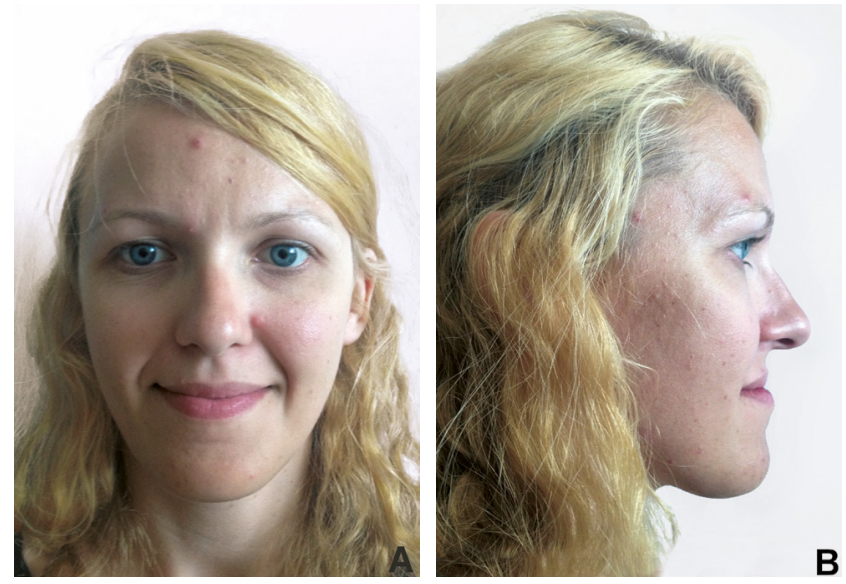

Fig. 2. Facial views before surgery A - frontal view; B - profile view. 

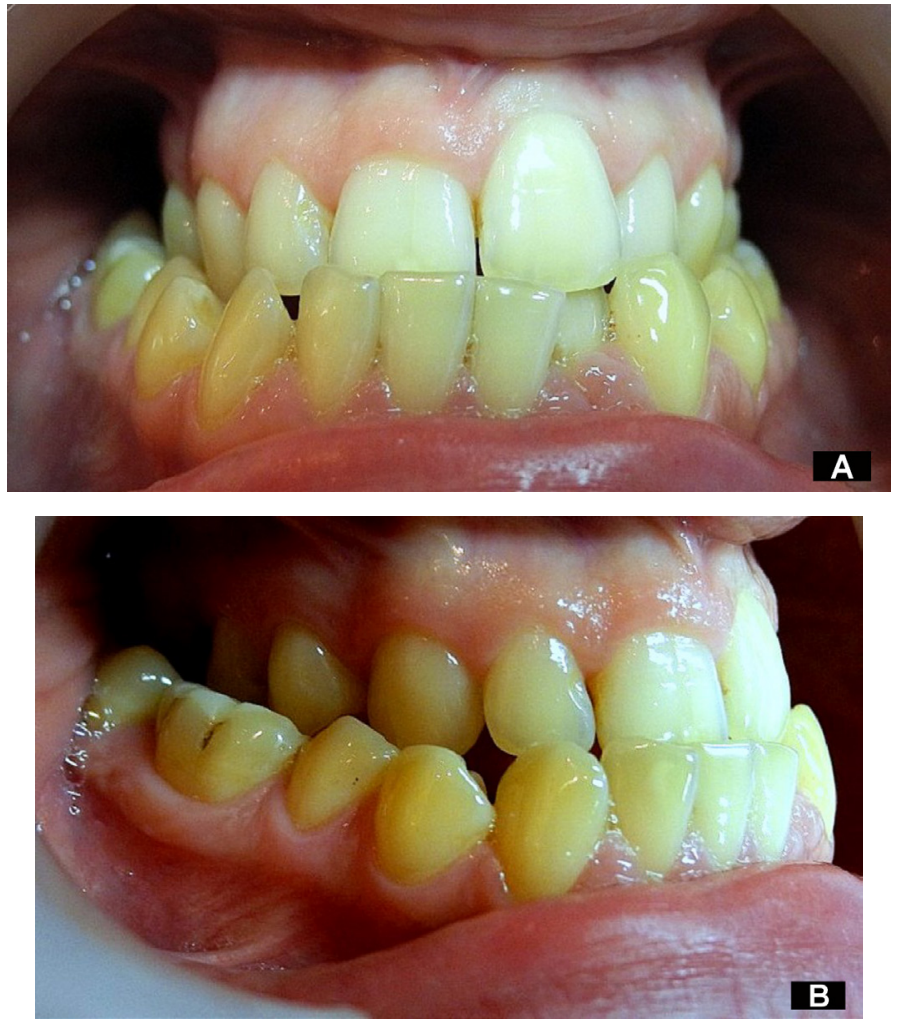

Fig. 3. A-C - occlusal views before treatment; D - maxillary constriction

Transpalatal distraction is one of the approaches used for increasing the transverse maxillary dimension. Introduced by Maurice Y. Mommaerts in 1999, TPD works on a principle of distraction osteogenesis, increasing the maxillary base width and its transverse dimension. What is innovative in comparison with surgically assisted rapid maxillary expansion (SARME) is using a bone-anchored transpalatal distractor as the force-generating device. Placed within the palatal bone, the distractor exerts force on the palatine process of the maxilla only, without any adverse effect on the lateral teeth. ${ }^{10,11}$

As part of preparation for TPD, an upper fixed appliance was used (the Roth system with the 0.018 slot size) and the $0.016 \times 0.022$ passive stainless steel (SS) archwire (Natural Arch Form III; American Orthodontics, Sheboygan, USA) was engaged.

Next, the surgery was scheduled and performed under general anesthesia. The Le Fort I osteotomy was performed from the symmetrical approaches in the oral vestibule and maxillary labial frenulum, including the bilateral separation of the maxilla from the pterygoid processes of the sphenoid bone and the surgical mobilization of the midpalatal suture. After checking the mobility of the maxillary bones, the size $16 \mathrm{UNI}-\mathrm{Smile}^{\circledR}$ transpalatal distractor (Titamed, Kontich, Belgium) was fixed on the hard palate at the level of the second premolars. The abutment plates were located horizontally at $1.0 \mathrm{~cm}$ from the gingival margin, perpendicular to the skeletal line of the midpalatal suture. The activation of the intraoperative distractor yielded a 1.0-millimeter-wide diastema.
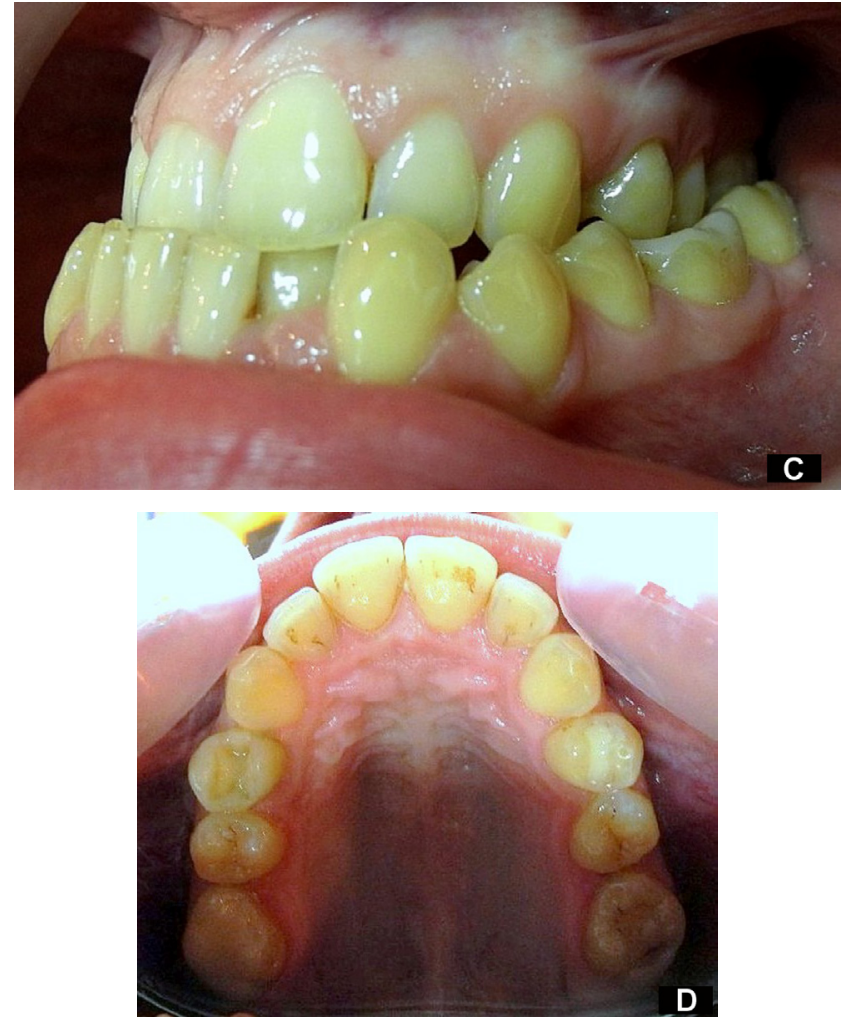

The wound was closed using 4-0 absorbable sutures (Safil ${ }^{\circledR}$; B. Braun Austria $\mathrm{GmbH}$, Maria Enzersdorf, Austria). Medical treatment involved the administration of periand postoperative preventive antibiotic therapy, analgesics, antiedema agents, and anticongestant nasal drops.

The distraction protocol involved the 3 standard stages of latency, distraction and retention. The surgery was followed by a 6-day latency phase. The distractor did not expand spontaneously owing to the blocking screw, placed and tightened intraoperatively. As the blocking screw was removed, the patient was instructed to activate the device herself by performing 2 rotations of the screw (each being a quarter turn) daily, which translates into an expansion of $0.5 \mathrm{~mm}$ a day. The duration of the active treatment phase depends on transverse maxillary deficiency. In this particular case, the distraction phase lasted for 15 days. The total number of activations was 29 , which corresponded to the overall expansion of $7.25 \mathrm{~mm}$. After the completion of the active treatment, the blocking screw was placed and tightened again. The follow-up X-ray, intraoral photographs and craniofacial CT scan with 3D image rendering were done. Six weeks after the completion of distraction, orthodontic treatment was commenced.

The aim of orthodontic treatment was to reshape the upper arch, close the diastema caused by palatal distraction and reposition the maxillary teeth. Additionally, a fixed appliance was used on the lower arch to achieve the appropriate inclination of the lower incisors and torque of the lateral teeth. As a result, the complete decompensation of skeletal class III malocclusion was achieved. 
The distractor was evacuated during an outpatient procedure under local anesthesia. As the retention period ended, we did the follow-up imaging, including OPG, a cranial X-ray PA $0^{\circ}$, cephalometric radiographs, and intraoral photographs (Fig. 4) as well as a craniofacial CT scan with 3D image rendering (Fig. 5).

The next stage of the complex orthodontic and surgical treatment was bimaxillary osteotomy (BIMAX). Historically, the first maxillo-mandibular surgery was performed by Hugo L. Obwegeser back in 1970. ${ }^{12}$ Trauner and Obwegeser also developed the commonly used bilateral sagittal split osteotomy (BSSO) in 1955, which was later modified by the Italian surgeon Dal Pont in $1961 .{ }^{13-15}$ Further modifications to the BSSO technique were introduced by Hunsuck (1968) and Epker (1977). Nevertheless, the main principle postulated by Obwegeser and Dal Pont has remained unchanged. ${ }^{16}$

Having obtained the extra- (Fig. 6) and intraoral photographs (Fig. 7), OPG (Fig. 8), cephalometric radiographs (Fig. 9), plaster models, and occlusal records from an articulator, the surgery was planned.

Maxillary and mandibular dental casts mounted on an articulator were used as a surgery phantom. During this procedure, interocclusal relationships were recorded and used for making surgical templates - an intermediate occlusal splint, which determined maxillary repositioning, and a final occlusal splint, which determined mandibular repositioning. An anterior maxillary repositioning of $5 \mathrm{~mm}$ was planned, with the slight impaction and clockwise rotation $(3 \mathrm{~mm})$ of the posterior maxillary segment. A posterior mandibular repositioning

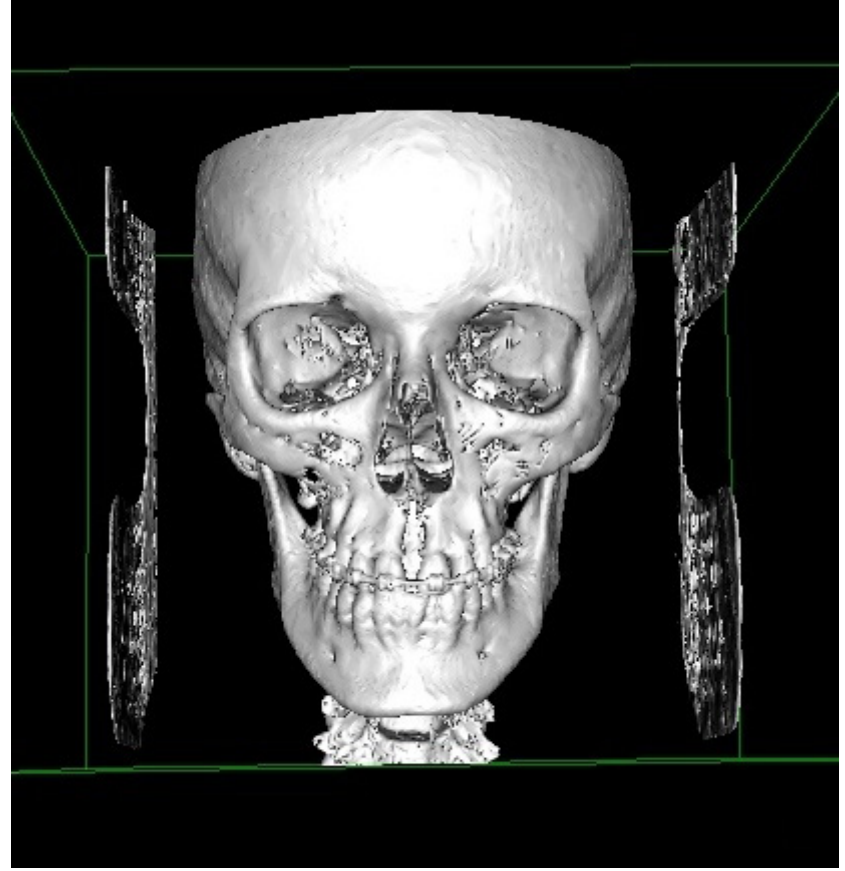

Fig. 5. Three-dimensional (3D) reconstruction of the facial skeleton before the removal of the transpalatal distractor

of $3 \mathrm{~mm}$ was planned, with the slight rotation of the distal segment to the left for midline correction and skeletal symmetry.

Prior to the surgery, surgical archwires, i.e., the $0.017 \times 0.025$ full-sized SS archwires (Natural Arch Form III; American Orthodontics) with additional hooks to attach intermaxillary elastics were applied.
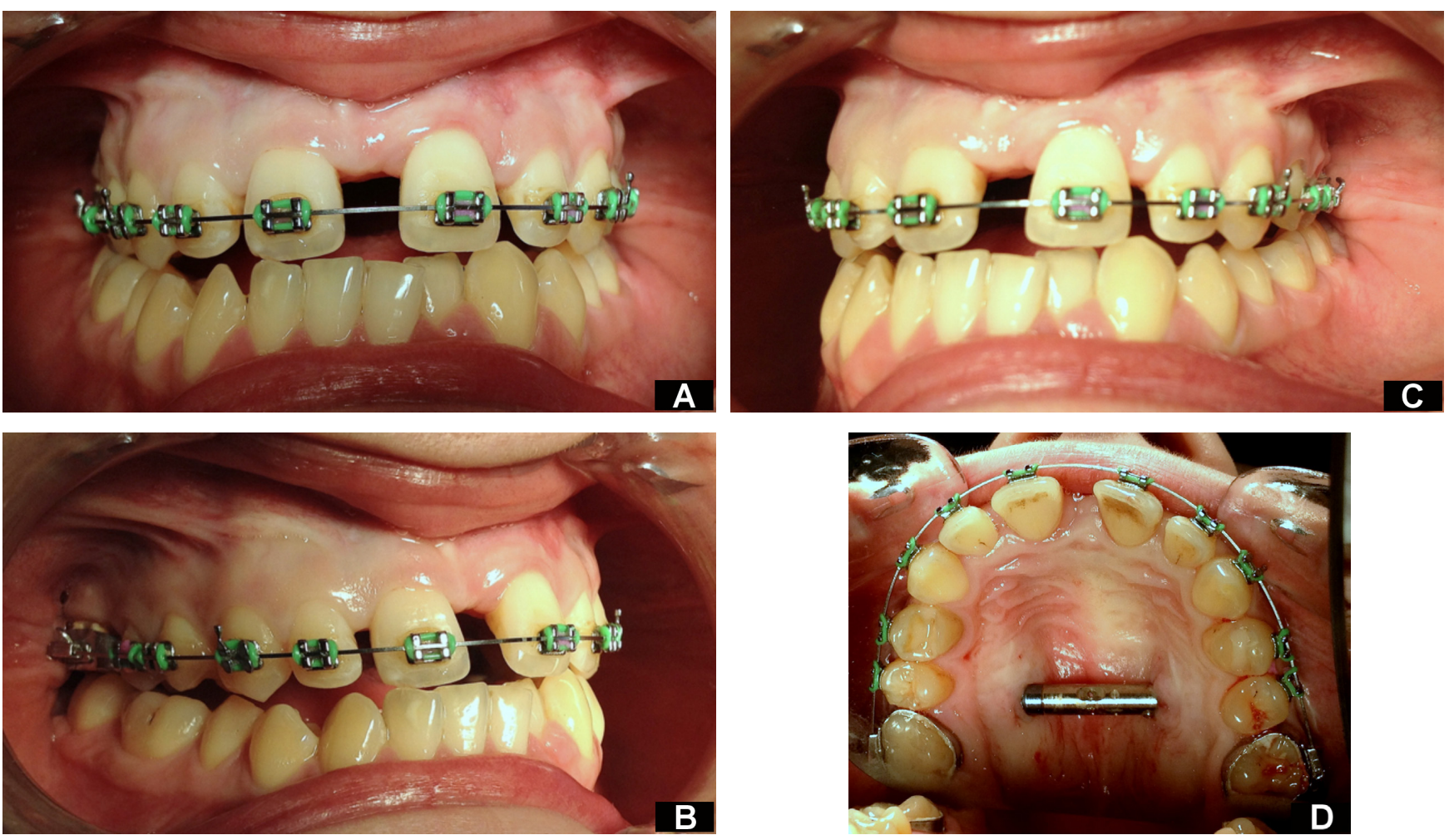

Fig. 4. A-C - occlusion changes after maxillary distraction; D - view of the maxilla after distraction 

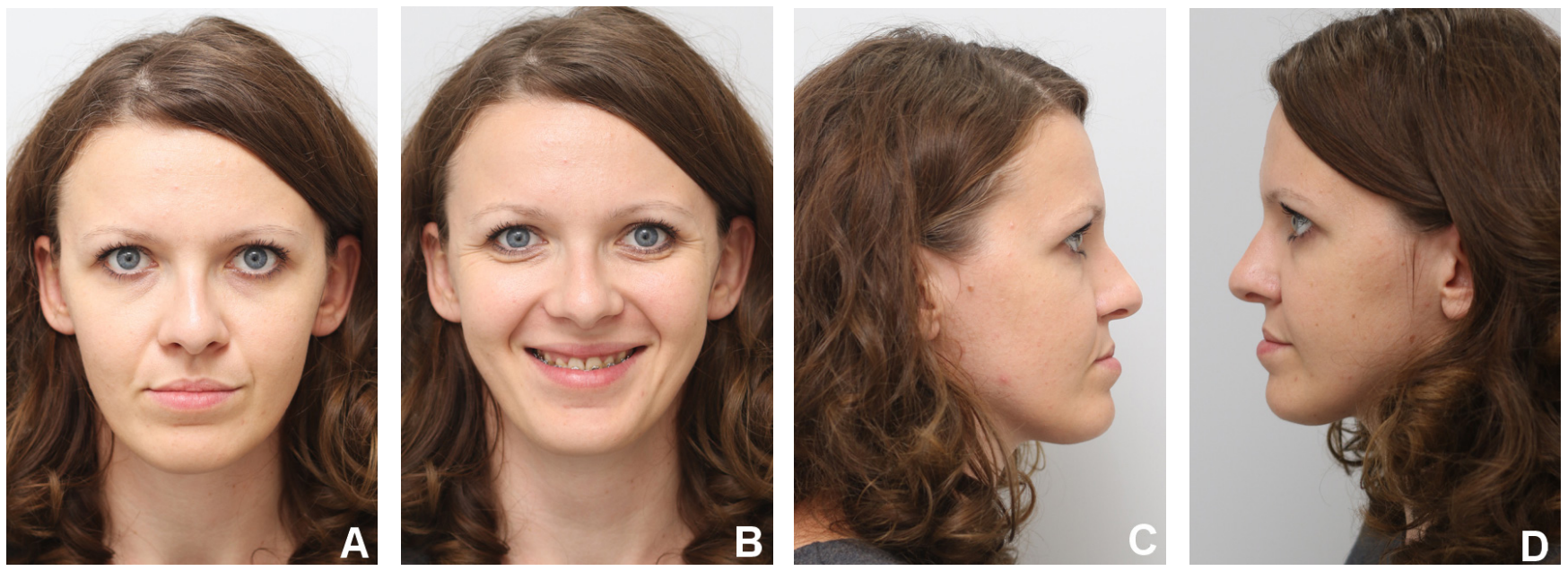

Fig. 6. Facial views before bimaxillary osteotomy (BIMAX) A - frontal view; B - smile; C, D - profile views.
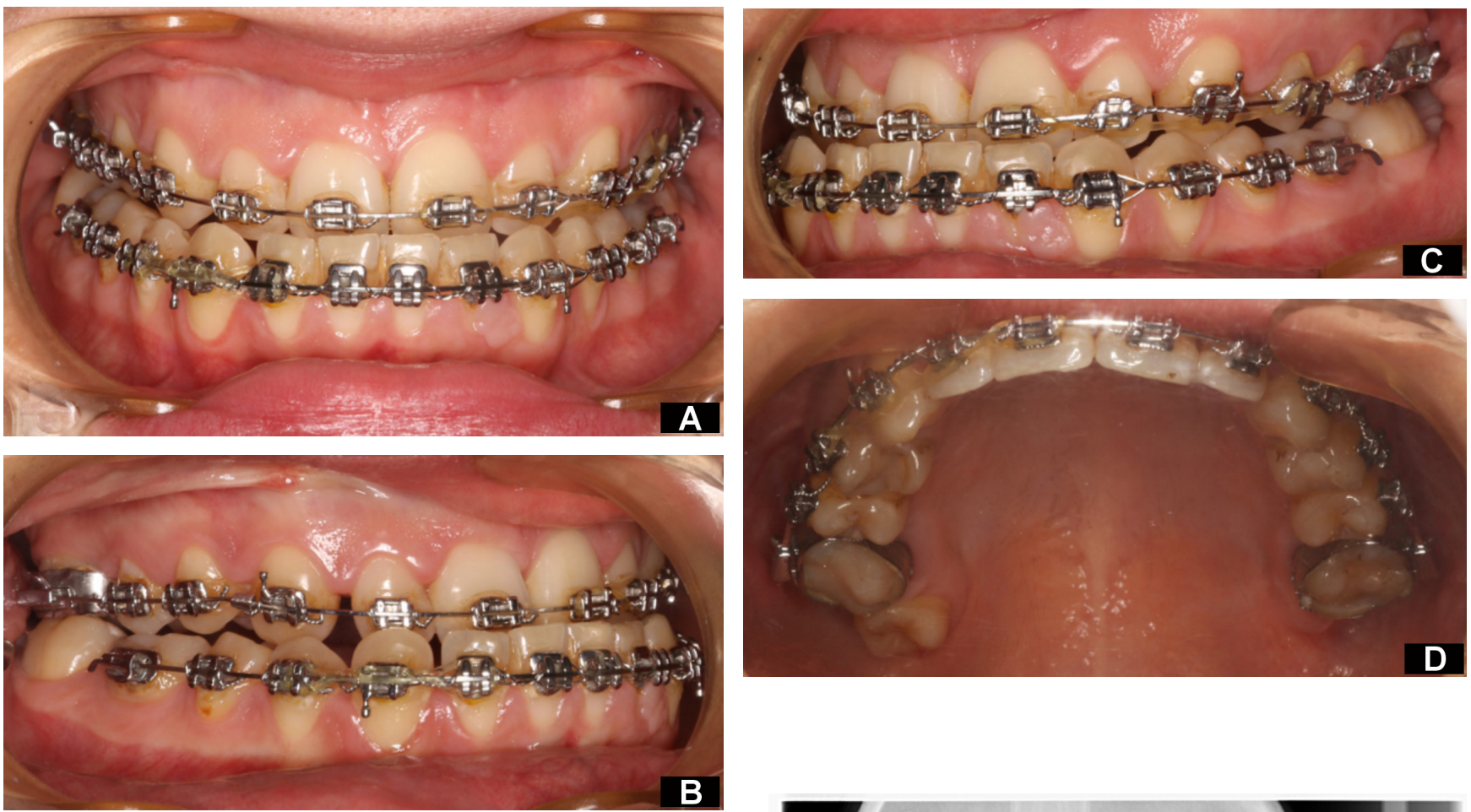

Fig. 7. A-C - occlusion before BIMAX; D - maxilla before BIMAX

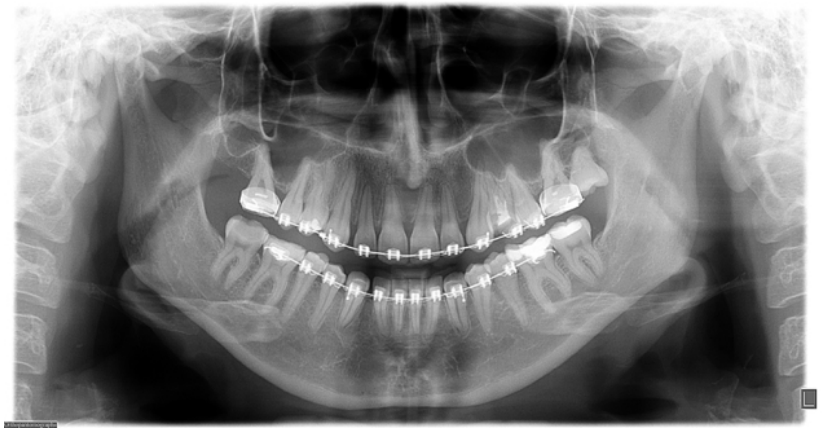

Fig. 8. Orthopantomogram (OPG) before BIMAX

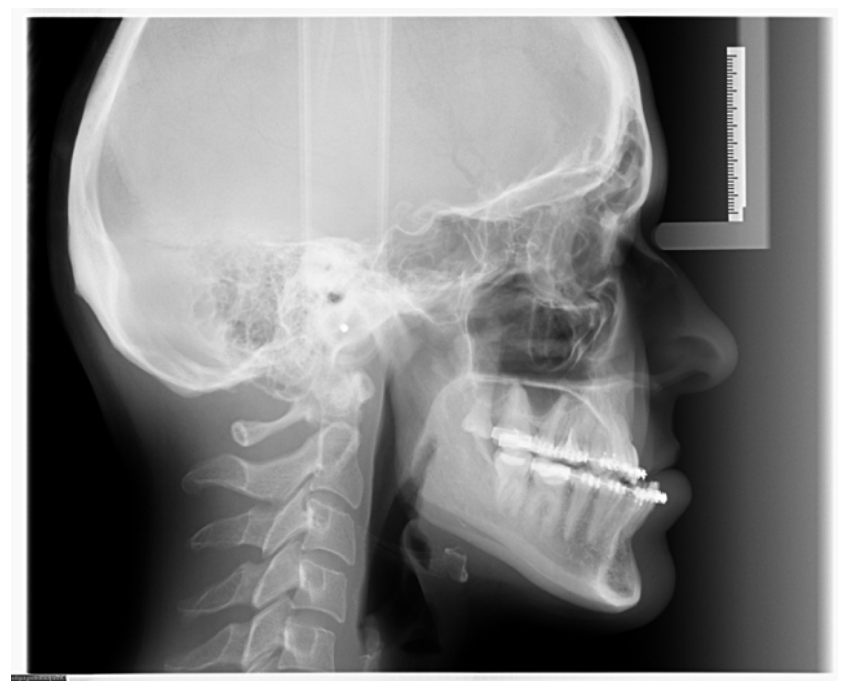

Fig. 9. Lateral cephalogram before BIMAX 
The surgery was performed under general anesthesia. The anterior and lateral maxillary surface was exposed using the maxillary vestibular approach. Next, the Le Fort I osteotomy was performed, followed by lateral and septal osteotomy and the separation of the pterygomaxillary junction (PMJ) as well as the down-fracture and mobilization of the maxilla. The osteosynthesis of the bone fragments in the predetermined position was performed using miniplates and screws 2.3 (Titamed). Subsequently, BSSO (Obwegeser-Dal Pont) was performed and the distal segment was positioned as planned. The mandibular fragments were fixed using bicortical screws 2.3 (Titamed), 3 screws on each side. Medical peri- and postoperative treatment involved the administration of antibiotics, antiedema agents and nasal sprays, which lubricated the nasal passages and maintained their patency. In order to provide additional support, class III intermaxillary elastics were used from the $1^{\text {st }}$ day postoperatively. The follow-up OPG (Fig. 10) and cephalometric radiographs (Fig. 11) were also performed.

In the $1^{\text {st }}$ week postoperatively, the patient started a masticatory rehabilitation program, involving the orbicularis oris muscle exercises and passive mouth-opening exercises. In the $2^{\text {nd }}$ week, the patient started mild, pain-free active mouth-opening exercises. In subsequent weeks, the physical therapy program was modified by increasing

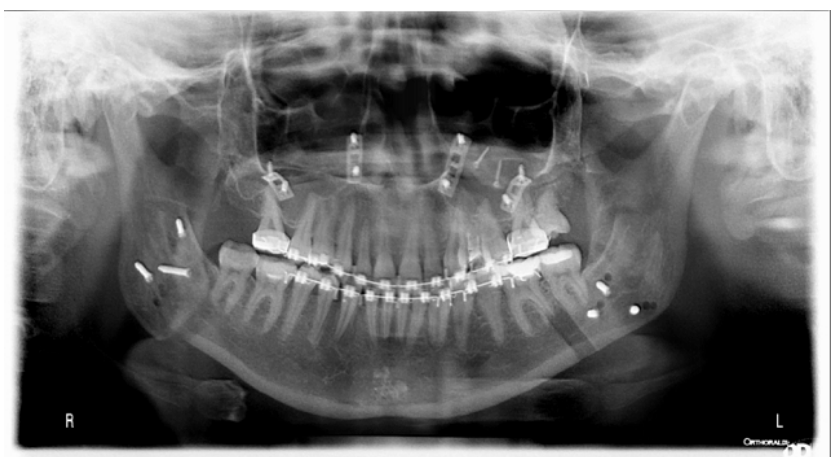

Fig. 10. OPG after BIMAX

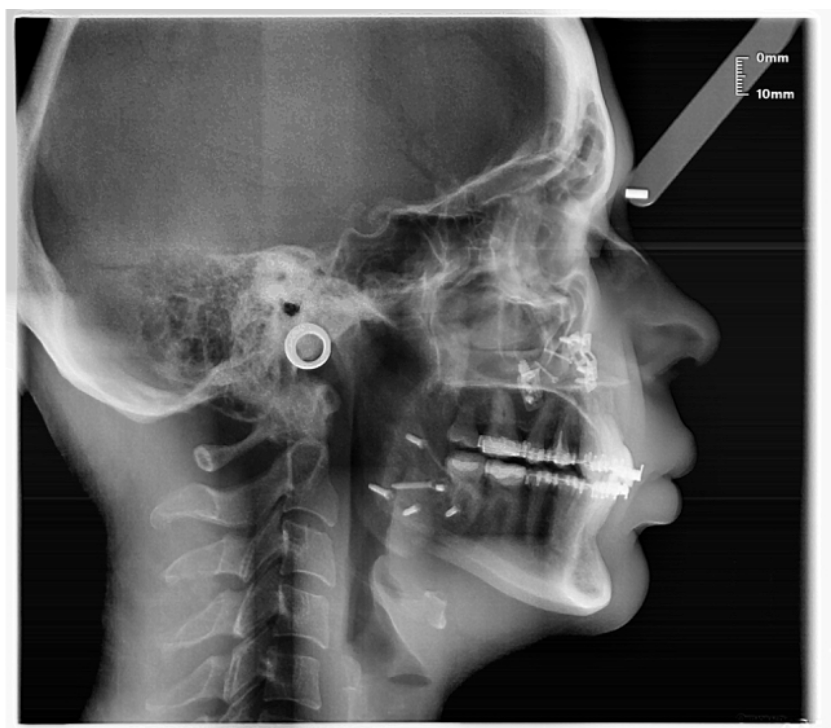

Fig. 11. Lateral cephalogram after BIMAX the exercise frequency as well as the muscular force and the range of motion (ROM) of the temporomandibular joint (TMJ), and simultaneously shortening the wearing time of the intermaxillary elastics.

In the $6^{\text {th }}$ week postoperatively, the surgical archwires were removed and replaced with the archwires enabling the occlusion to settle - the $0.017 \times 0.025$ nickel-titanium $(\mathrm{NiTi})$ archwire (Form III NT3 ${ }^{\mathrm{TM}} \mathrm{SE} \mathrm{NiTi}$; American Orthodontics) and the $0.017 \times 0.025$ Turbo Arch NiTi archwire $\left(\mathrm{Ormco}^{\mathrm{TM}}\right.$, Chisinau, Moldova). The patient was advised to wear the intermaxillary elastics at night. While settling the occlusion, the premature occlusal contacts and occlusal barriers were corrected so as to ensure proper resting and functional occlusal relationships (Fig. 12). The complex surgical-orthodontic treatment led to the improvement of facial features (Fig. 13).

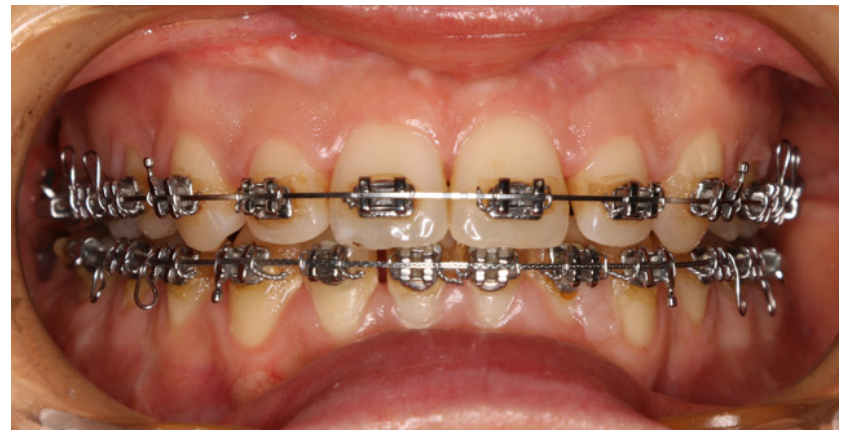

Fig. 12. Occlusion after treatment
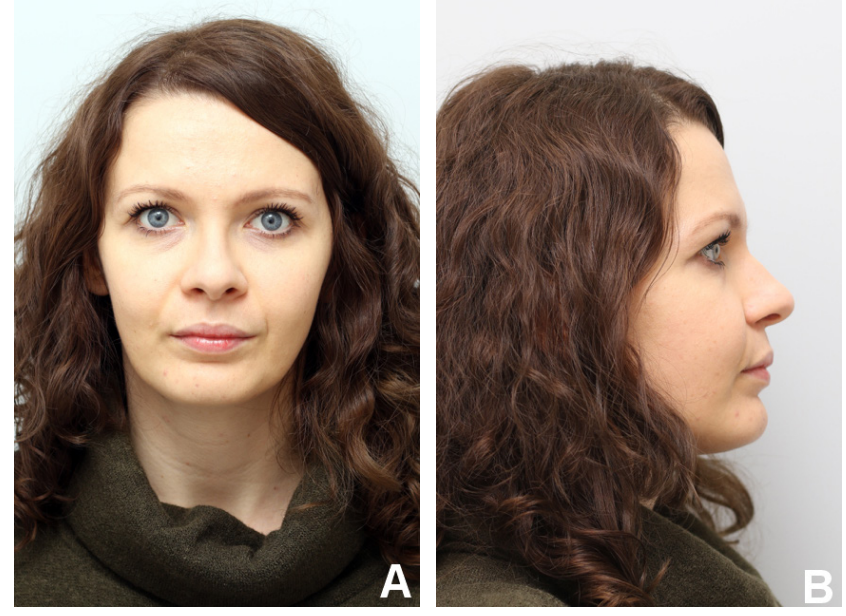

Fig. 13. Facial views after treatment A - frontal view; $B, C$ - profile views.

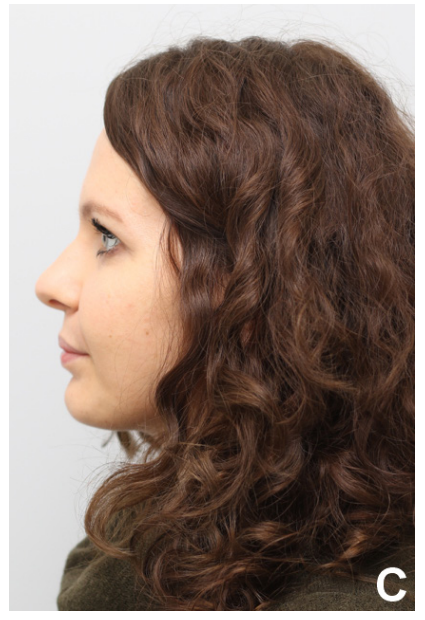




\section{Conclusions}

A complex orthodontic and surgical approach is a key to the successful correction of skeletal malocclusion. It is crucial to take time to educate the patient on the assumptions of this multidisciplinary approach and provide all necessary explanations. This complex orthodontic and surgical management significantly improved facial harmony, increased nasal volume, caused a shift from mouth breathing to nasal breathing, and restored normal occlusal relationships. Despite its complexity and duration, in the case of severe skeletal malocclusion, multidisciplinary treatment is a method of choice, aiming at determining and correcting the underlying cause of the abnormality, which in turn offers a better chance of achieving a stable effect and patient satisfaction.

\section{ORCID iDs}

Rafał Nowak (i) https://orcid.org/0000-0001-9375-0369

Małgorzata Rzepecka-Skupień (1) https://orcid.org/0000-0002-6947-3928

Ewa Zawiślak (D) https://orcid.org/0000-0002-0415-3982

\section{References}

1. Converse JM, Shapiro $\mathrm{HH}$. Treatment of developmental malformations of the jaw. Plast Reconstr Surg (1946). 1952;10(6):473-510.

2. Panula K. Correction of dentofacial deformities with orthognatic surgery. Outcome of treatment with special reference to costs, benefits and risks. Department of Oral and Maxillofacial Surgery, Institute of Dentistry, University of Oulu, Finland, 2003 (PhD thesis).

3. Proffit WR, Turvey TA, Phillips C. Orthognathic surgery: A hierarchy of stability. Int J Adult Orthodon Orthognath Surg. 1996;11(3):191-204.

4. Champy M, Lodde JP. Mandibular osteosyntheses: Localization of osteosyntheses depending on the mandibular stresses [in French]. Rev Stomatol Chir Maxillofac. 1976;77(8):871-876.

5. Robinson RC, Holm RL. Orthognathic surgery for patients with maxillofacial deformities. AORN J. 2010;92(1):28-49;quiz 50-52.

6. Agnihotry A, Fedorowicz Z, Nasser M, Gill KS. Resorbable versus titanium plates for orthognathic surgery. Cochrane Database Syst Rev. 2017;10:CD006204.

7. Kulewicz M. Distraction osteogenesis in orthognathic surgery [in Polish]. Acta Clin. 2001;1(2):117-128.

8. Laptook T. Conductive hearing loss and rapid maxillary expansion. Am J Orthod. 1981;80(3):325-331.

9. Chrcanovic BR, Custódio AL. Orthodontic or surgically assisted rapid maxillary expansion. Oral Maxillofac Surg. 2009;13(3):123-137.

10. Mommaerts MY. Transpalatal distraction as a method of maxillary expansion. Br J Oral Maxillofac Surg.1999;37(4):268-272.

11. Matteini C, Mommaerts MY. Posterior transpalatal distraction with pterygoid disjunction: A short-term model study. Am J Orthod Dentofacial Orthop. 2001;120(5):498-502.

12. Bell RB. A history of orthognathic surgery in North America. J Oral Maxillofac Surg. 2018;76(12):2466-2481.

13. Obwegeser HL. Some innovative evolutions in surgery of the craniomaxillofacial skeleton. J Craniomaxillofac Surg. 2017;45(9):1361-1377.

14. Obwegeser HL. Orthognathic surgery and a tale of how three procedures came to be: A letter to the next generations of surgeons. Clin Plastic Surg. 2003;34(3):331-355.

15. Nocini PF, Chiarini L, Bertossi D. Cosmetic procedures in orthognathic surgery. J Oral Maxillofac Surg. 2011;69(3):716-723.

16. Steinhäuser EW. Historical development of orthognathic surgery. J Craniomaxillofac Surg. 1996;24(4):195-204. 